\title{
Planar Motion Mechanism Test of the Mobile Harbor Running in Design Speed in Circulating Water Channel
}

\author{
† Hyeon-Kyu Yoon ·Joo-Nyun Kang* \\ † Dept. of Naval Archtecture \& Marine Engineering, Changwon National University, Changwon 641-773, Republic. of Korea \\ * Dept. of Naval Archtecture \& Marine Engineering, University of Strathclyde, Glasgow, G40LZ, United Kingdom
}

\begin{abstract}
Mobile Harbor (MH) is a new transportation platform that can load and unload containers onto and from very large container ships at sea. It could navigate near harbors where several vessels run, or it could navigate through very narrow channels. In the conceptual design phase when the candidate design changes frequently according to the various performance requirements, it is very expensive and time-consuming to carry out model tests using a large model in a large towing tank and a free-running model test in a large maneuvering basin. In this paper, a new Planar Motion Mechanism(PMM) test in a Circulating Water Channel (CWC) was conducted in order to determine the hydrodynamic coefficients of the MH. To do this, PMM devices including three-component load cells and inertia tare device were designed and manufactured, and various tests of the MH such as static drift test, pure sway test, pure yaw test, and drift-and-yaw combined test were carried out. Using those coefficients, course-keeping stability was analyzed. In addition, the PMM tests results carried out for the same KCS (KRISO container ship) were compared with our results in order to confirm the test validity.
\end{abstract}

Key words : Mobile Harbor, Planar Motion Mechanism test, Hydrodynamic coefficients, Maneuverability, Circulating water channel

\section{Introduction}

Mobile Harbor (MH) is a new conceptual platform that can load containers onto and unload containers from very large container ships anchored at sea near small ports, which large ships can not approach in shallow water, and new loading facilities of large gantry cranes are not equipped with. After the $\mathrm{MH}$ is loaded or unloaded, it navigates around near the harbor where a number of vessels run, or it runs through narrow water channels. Therefore, its maneuverability is as important as its seakeeping performance, which is important in loading and unloading containers at sea. For this reason, the maneuverability of $\mathrm{MH}$ must be analyzed in the initial design phase.

The maneuvering performance of a ship is assessed by two methods. The first one uses a simulation technique after establishing the equations of motion based on the empirical formulae or the captive model test results for the hydrodynamic coefficients which are the parameters in the model of the hydrodynamic force acting on a maneuvering ship (Kobayashi et al, 1995; Abkowitz, 1969). The other one is to carry out a free-running model test (Kim, 2004). The former method can be widely used in the initial or conceptual design phase at the time when the shape of a ship could be changed frequently following various performance requirements. The empirical formulae for the hydrodynamic coefficients are the statistical regression results based on a number of captive model test results of monohull vessels for a long time (Kobayashi, 1995; Lewis, 1989). Unfortunately, since the $\mathrm{MH}$ was designed in a catamaran shape, well-known formulae could not be applied to find out its hydrodynamic coefficients. For ships with an unconventional shape such as the $\mathrm{MH}$, a captive model test using the Planar Motion Mechanism (PMM) is necessary to obtain the hydrodynamic coefficients.

In the initial design phase when the change in the hull form of the $\mathrm{MH}$ could occur frequently, it is very expensive and time-consuming to carry out model tests using a large model in a large towing tank. For this reason, it is more convenient to obtain the hydrodynamic coefficients of the catamaran-shaped $\mathrm{MH}$ using a simple test method.

In this study, a new PMM test in a Circulating Water Channel (CWC) was carried out in order to find out the hydrodynamic coefficients of the MH. To do this, PMM devices including a three-component load cell which measures surge, sway external forces and yaw external moment acting on a ship and an inertial measuring device which measures the mass moment of inertia in yaw were designed and manufactured. The PMM tests such as static drift test, pure sway test, pure yaw test, and drift-and-yaw

\footnotetext{
† Corresponding author, hkyoon@changwon.ac.kr 055)213-3683

* joonyun.Kang@gmail.com +44(141)330-2648
} 
combined test were carried out for the full and middle loading conditions of the $\mathrm{MH}$ at the $\mathrm{CWC}$ of Changwon National University (Sewon Engineering Co., 2009). Using the obtained hydrodynamic coefficients, we analyzed the course-keeping stabilities of the two loading conditions. In addition, PMM tests of KCS (KRISO, formerly MOERI, container ship) were conducted in the CWC and its drift test results were compared with those conducted at MOERI (Kim et al, 2009).

\section{Equations of motion}

\subsection{Equations of motion}

In order to describe the maneuvering motion of the $\mathrm{MH}$ in the horizontal plane, two kinds of coordinate systems were adopted as shown in Fig. 1.

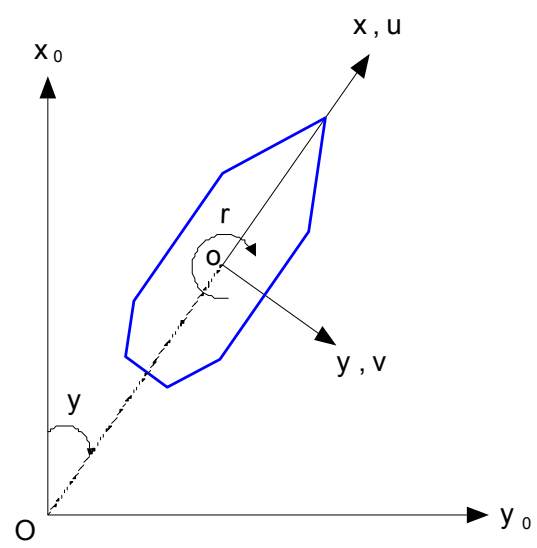

Fig. 1 Coordinates systems and definition of symbols

Since the roll of the catamaran-shaped $\mathrm{MH}$ does not occur largely during running or turning, it should be enough to describe its motion in the horizontal plane only. The linear displacement is represented in the earth-fixed frame denoted by $O-x_{0} y_{0}$, while the equations of motion are described in the body-fixed frame denoted by $o-x y$ (Fossen, 1994). Hydrodynamic forces and moment acting on a ship can be described more easily in the body-fixed frame than in the earth-fixed frame. The origin of the body-fixed frame is the cross point of the longitudinal center line and the midship section. The symbols $u, v, r$ and $\psi$ represent surge and sway velocities, yaw rate, and yaw Euler angle, respectively. The equations of motion in the horizontal plane of the $\mathrm{MH}$ are described based on Newton's second law as follows:

$$
\begin{aligned}
& m\left(\dot{u}-v r-x_{G} r^{2}\right)=X_{H}+X_{P}, \\
& m\left(\dot{v}+u r+x_{G} \dot{r}\right)=Y_{H}+Y_{P} \\
& I_{z z} \dot{r}+m x_{G}(\dot{v}+u r)=N_{H}+N_{P}
\end{aligned}
$$

where $m, I_{z z}$ and $x_{G}$ are mass, the mass moment of inertia about the $z$-axis, and $X, Y$ and $N$ are external forces and moment consisting hydrodynamic and thrust terms, which are denoted as subscripts $H$ and $P$. Since the $\mathrm{MH}$ changes its course with changing the directions of the thrusters, the external forces and moment consist of the only terms related to the bare hull and thrusters.

\subsection{Models of external force and moment}

Even though the main goal of this thesis is to model hydrodynamic force and moment acting on the bare hull of the maneuvering $\mathrm{MH}$, the models of surge hydrodynamic force and the thrusters are suggested as well as the models of sway hydrodynamic force and yaw hydrodynamic moment. The surge hydrodynamic force model can be described as follows:

$$
X_{H}=X_{\dot{u}} \dot{u}+X_{v v} v^{2}+X_{v r} v r+X_{r r} r^{2}+X(u),
$$

where, $X_{\dot{u}}, X_{v v}, \cdots, X_{r r}$ are hydrodynamic coefficients of the surge hydrodynamic force model, which mean the hydrodynamic force slopes with respect to motion variables denoted as the subscripts such as $\dot{u}, v v, \cdots, r r$. The dot on a motion variable means its time derivative. $X(u)$ is the resistance which consists of frictional drag and residual drag based on Froude's corresponding law.

The force and moment model of the thrusters could be suggested as follows:

$$
\begin{aligned}
X_{P} & =\sum_{i=1}^{n_{P}}(1-t) \rho n_{i}^{2} D_{p}^{4} K_{T}\left(J_{P_{i}}\right) \cos \alpha_{i} \\
Y_{P} & =\sum_{i=1}^{n_{P}}(1-t) \rho n_{i}^{2} D_{p}^{4} K_{T}\left(J_{P_{i}}\right) \sin \alpha_{i} \\
N_{P} & =\sum_{i=1}^{n_{P}}(1-t) \rho n_{i}^{2} D_{p}^{4} K_{T}\left(J_{P_{i}}\right) x_{P_{i}} \sin \alpha_{i}
\end{aligned}
$$

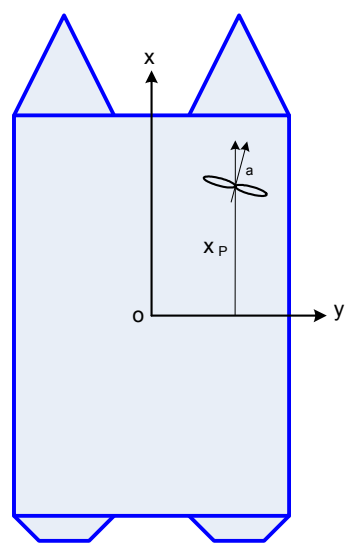

Fig. 2 Deflection angle and $x$-coordinate of the position of the thrusters 
where $t, n, D_{p}, K_{T}$, and $J_{p}$ are the thrust deduction coefficient, revolution per second (rps), diameter, thrust coefficient, and advance ratio at the propeller position. Subscript $i$ and $n_{p}$ denote the $i$ th thruster and the number of thrusters. $\alpha$ and $x_{p}$ are the deflection angle of the thrusters and the $x$-coordinate of the position with respect to body-fixed frame, as depicted in Fig. 2.

Sway hydrodynamic force and yaw hydrodynamic moment acting on the bare hull of the maneuvering $\mathrm{MH}$ were modeled as follows:

$$
\begin{aligned}
Y_{H}= & Y_{\dot{v}} \dot{v}+Y_{\dot{r}} \dot{r}+Y_{v} v+Y_{r} r \\
& +Y_{v v v} v^{3}+Y_{v v r} v^{2} r+Y_{v r r} v r^{2}+Y_{r r r} r^{3} \\
N_{H}= & N_{\dot{v}} \dot{v}+N_{\dot{r}} \dot{r}+N_{v} v+N_{r} r \\
& +N_{v v v} v^{3}+N_{v v r} v^{2} r+N_{v r r} v r^{2}+N_{r r r} r^{3}
\end{aligned}
$$

where, $Y_{\dot{v}}, Y_{\dot{r}}, \cdots, Y_{r r r}$ and $N_{\dot{v}}, N_{\dot{r}}, \cdots, N_{r r r}$ are sway and yaw hydrodynamic coefficients, respectively, which will be obtained using the results of the PMM tests carried out in the CWC at Changwon National University.

Hydrodynamic coefficients in Eq. (2) and Eq. (4) were non-dimensionalized using SNAME's convention and denoted as the prime symbol as follows:

$$
F=\frac{F}{\frac{\rho}{2} L^{2} V^{2}} \text { and } M=\frac{M}{\frac{\rho}{2} L^{3} V^{2}},
$$

where $F$ and $M$ are the hydrodynamic force and moment, respectively, $L$ and $V$ are the length between perpendiculars and the speed of the $\mathrm{MH}$, and $\rho$ is the fluid density.

\section{Test facilities}

\subsection{Circulating water channel}

The CWC at Changwon National University, which is depicted in Fig. 3, was built in August 2009. It is a relatively small academic channel of which principal dimensions are described in Table 1.

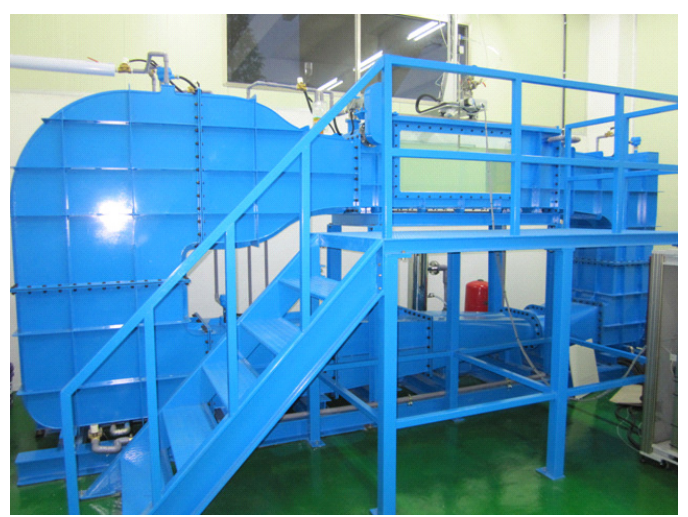

Fig. 3 CWC at Changwon National University
Table 1 Principal particulars of the $\mathrm{CWC}$ at Changwon National University

\begin{tabular}{|c|c|c|}
\hline \multicolumn{2}{|c|}{ Item } & Description \\
\hline \multicolumn{2}{|c|}{ Type } & $\begin{array}{c}\text { Two-impeller and } \\
\text { vertical circulation }\end{array}$ \\
\hline \multicolumn{2}{|c|}{ Water capacity } & Approx. 3 ton \\
\hline \multirow{2}{*}{ size } & Main body & L5.0 $\times$ W0.6 $\times \mathrm{H} 2.2 \mathrm{~m}$ \\
\cline { 2 - 4 } & Test section & L2.0 $\times \mathrm{W} 0.6 \times \mathrm{H} 0.6 \mathrm{~m}$ \\
\hline \multicolumn{2}{|c|}{ Flow speed } & $0.1 \sim 1.0 \mathrm{~m} / \mathrm{s}$ \\
\hline
\end{tabular}

In order to confirm the relationship between selected rpm of the impeller and the flow speed, we conducted a flow speed measurement test. Three sections which were $0.4 \mathrm{~m}$ forward, $0.0 \mathrm{~m}$, and $0.4 \mathrm{~m}$ afterward from the center were selected. Twelve points divided by $0.05 \mathrm{~m}$ intervals were selected in the transverse direction from $0.05 \mathrm{~m}$ to $0.55 \mathrm{~m}$, and 21 points divided by $0.01 \mathrm{~m}$ interval were selected in a downward direction from $0.03 \mathrm{~m}$ from the free surface to $0.23 \mathrm{~m}$.

Fig. 4 shows the measurement result of real flow speed in the center section when the setting speed was $0.5 \mathrm{~m} / \mathrm{s}$. The zeros of the transverse and vertical coordinates in Fig. 4 are $0.05 \mathrm{~m}$ and $0.03 \mathrm{~m}$ apart from the side wall and the free surface, respectively. The errors over $3 \%$ of setting flow speed occur near the free surface and under about $0.17 \mathrm{~m}$ downward. However, it seems that the error keeps under $3 \%$ in the area from 0.02 to $0.1 \mathrm{~m}$ in depth where the flow quality should be relatively important.

\subsection{Three-component load cell}

A three-component load cell was manufactured for the PMM test as shown in Fig. 5. The capacities for surge, sway and yaw for PMM are $5 \mathrm{~N}, 10 \mathrm{~N}$, and $1 \mathrm{Nm}$, respectively.

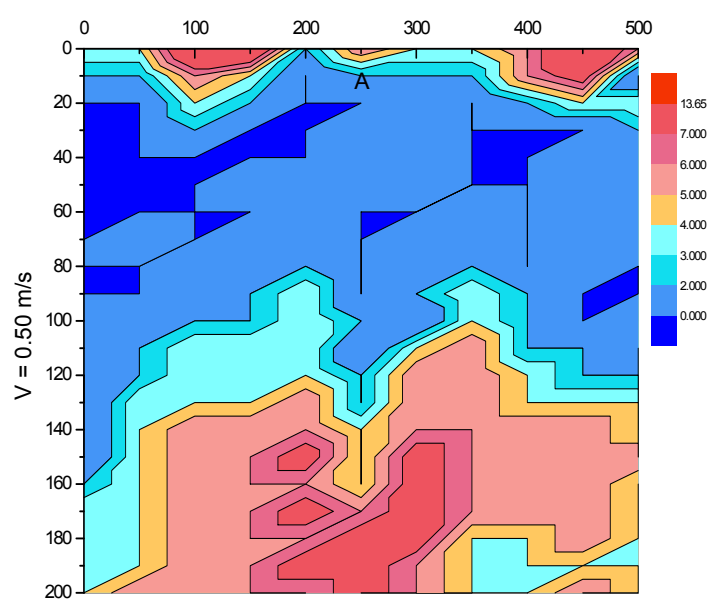

Fig. 4 Measured flow speed result at the center test section in case that setting flow speed is $0.5 \mathrm{~m} / \mathrm{s}$ 


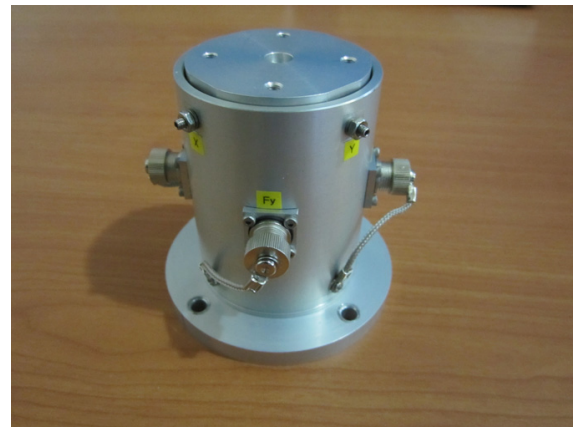

Fig. 5 Three-component load cell

\subsection{Planar Motion Mechanism}

The PMM device for CWC was manufactured in order to conduct the static drift, the pure sway, the pure yaw, and the drift-and-yaw combined tests. In addition, it can make a model's heave, roll, and pitch free and measure those displacements. Fig. 6 shows the PMM, and its main performance parameters are listed in Table 2.

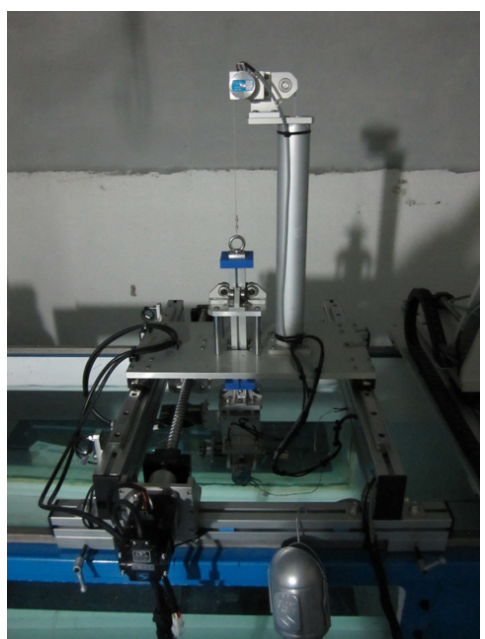

Fig. 6 PMM device for CWC

Table 2 Typical specifications of the PMM for CWC

\begin{tabular}{|c|c|}
\hline Item & Value \\
\hline Max. sway amplitude & $0.1 \mathrm{~m}$ \\
\hline Max. yaw amplitude & $10^{\circ}$ \\
\hline Max. oscillating frequency & $1 \mathrm{~Hz}$ \\
\hline Max. free heave & $\pm 0.1 \mathrm{~m}$ \\
\hline Max. free roll & $\pm 45^{\circ}$ \\
\hline Max. free pitch & $\pm 45^{\circ}$ \\
\hline
\end{tabular}

\subsection{Inertia-measuring device}

When dynamic PMM tests such as the pure sway test, the pure yaw test, and the combined test are performed, inertial force and moment as well as the hydrodynamic force and moment are measured. Therefore, the inertial force and moment must be excluded from the measured values. The mass is the same as the scaled value of a model ship and a mass moment of inertia of the model ship are estimated by inertia testing. The inertia test is conducted using the inertia-measuring device shown in Fig. 7.

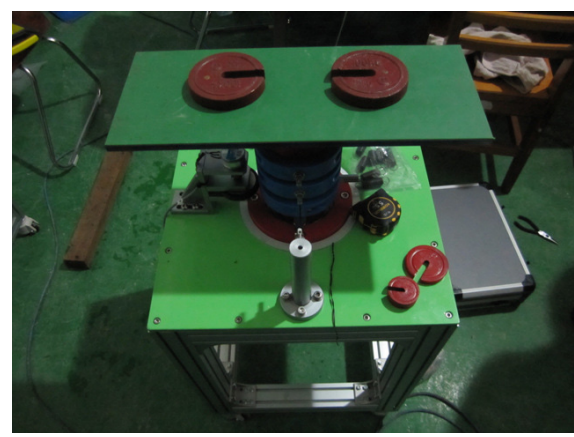

Fig. 7 Inertia-measuring device

\section{Test condition}

In order to determine the hydrodynamic coefficients of the $\mathrm{MH}$ in Eqs. (2) and (4), the resistance test, thruster open water test, self-propulsion and the PMM test have to be conducted. Since the CWC at Changwon National University is very small, the Reynolds number of a model should be in the transition range of the flow characteristics. It makes the resistance test results unreliable. Therefore, only the PMM tests of the KCS and the $\mathrm{MH}$ were carried out.

\section{1 Models}

The principal particulars of the models of the KCS and the $\mathrm{MH}$ are listed in Tables 3 and 4 . In the case of the $\mathrm{MH}$, all tests were conducted in the two loading conditions which are the full load and the middle load. Figs. 8 9 show the models of the KCS and the MH.

Table 3 Principal dimensions of the real ship and the model of the KCS

\begin{tabular}{|c|c|c|}
\hline Item & Real ship & Model \\
\hline Scale & - & 322 \\
\hline Lbp $(\mathrm{m})$ & 230 & 0.7143 \\
\hline Breadth $(\mathrm{m})$ & 32.2 & 0.1000 \\
\hline Draft $(\mathrm{m})$ & 10.8 & 0.0355 \\
\hline Wet. area $\left(\mathrm{m}^{2}\right)$ & 9645 & 0.09302 \\
\hline Displacement $\left(\mathrm{m}^{3}\right)$ & 52030 & 0.001558 \\
\hline LCG $(\mathrm{m})$ & -3.4 & -0.01056 \\
\hline $\mathrm{Cb}$ & 0.651 & 0.651 \\
\hline Design $\mathrm{speed}(\mathrm{m} / \mathrm{s})$ & 12.3456 & 0.6880 \\
\hline
\end{tabular}


Table 4 Principal dimensions of the real ship and the model of the full load and the middle load $\mathrm{MH}$

\begin{tabular}{|c|c|c|}
\hline Item & Real ship & Model \\
\hline Scale & - & 165 \\
\hline Lbp $(\mathrm{m})$ & 70 & 0.4242 \\
\hline Breadth $(\mathrm{m})$ & 33 & 0.2000 \\
\hline Draft $(\mathrm{m})$ & $5.3(4.0)$ & $0.0321(0.0242)$ \\
\hline Wet. area $\left(\mathrm{m}^{2}\right)$ & $2796(2304)$ & $0.1027(0.0846)$ \\
\hline Displacement $\left(\mathrm{m}^{3}\right)$ & $7469(5164)$ & 0.001663 \\
& & $(0.001149)$ \\
\hline LCG $(\mathrm{m})$ & $0.527(2.037)$ & $0.003194(0.01235)$ \\
\hline $\mathrm{Cb}$ & $0.5976(0.5609)$ & $0.5976(0.5609)$ \\
\hline Design $\mathrm{speed}(\mathrm{m} / \mathrm{s})$ & 4.1152 & 0.3204 \\
\hline
\end{tabular}

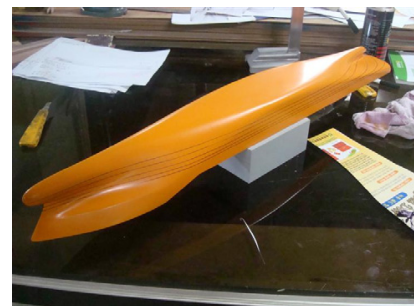

Fig. 8 KCS model

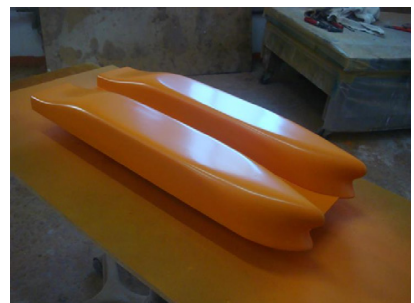

Fig. $9 \mathrm{MH}$ model

\subsection{Test matrix}

Test matrix for the PMM tests is listed in Table 5. In the case of the KCS, the same matrix of the PMM test in Table 5 was carried out except for the combined test. In Table $6, \beta$ is the drift angle.

Table 5 Test matrix for the PMM test

\begin{tabular}{|c|c|c|}
\hline \multirow{2}{*}{ Class } & \multicolumn{2}{|c|}{ Test condition } \\
\cline { 2 - 3 } & Variable & Values \\
\hline Static drift & $\beta$ & $0, \pm 2, \pm 4, \pm 6, \pm 8, \pm 12, \pm 15$ \\
\hline Pure sway & $\dot{v}^{\prime}$ & $0.04,0.08,0.12,0.16$ \\
\hline Pure yaw & $r^{\prime}$ & $0.15,0.20,0.30,0.40,0.50,0.70$ \\
\hline \multirow{2}{*}{ Combined } & $\beta$ & $\pm 4, \pm 8, \pm 12$ \\
\cline { 2 - 3 } & $r^{\prime}$ & $0.15,0.20,0.30,0.40,0.50$ \\
\hline
\end{tabular}

\section{Test results}

\subsection{Benchmark test}

We conducted benchmark tests for the results from the CWC at Changwon National University.

Fig. 10 shows the repeatability test for the drift test of the $\mathrm{MH}$. After finishing the first set of the drift test of the $\mathrm{MH}$, the second set was conducted. This shows that repeatability is guaranteed.

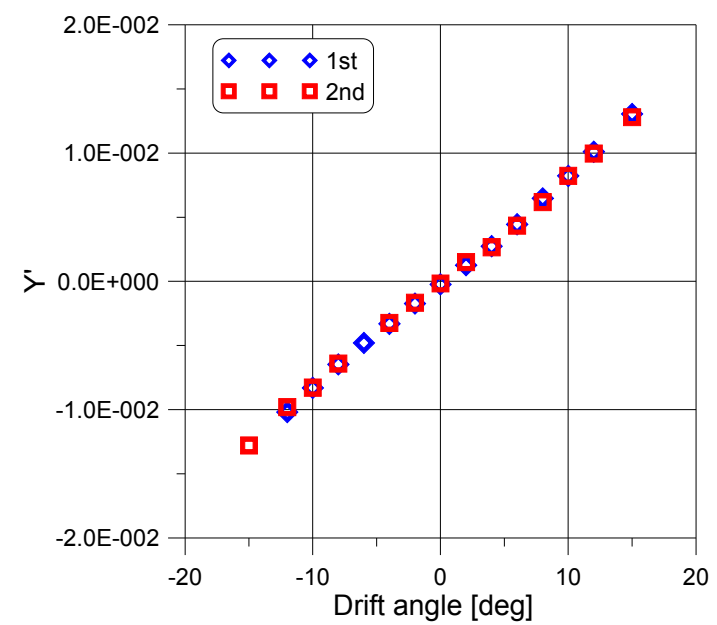

Fig. 10 Repeatability test of the drift test of the $\mathrm{MH}$

In order to confirm the performance of the new facility, the drift test results of the KCS were compared with those found by MOERI (Kim et al, 2009) indirectly as depicted in Fig. 11. The MOERI results were obtained when the propeller of the KCS was rotating at the self-propulsion point. However, since the results in this study are only for bare hulls, those results could not be compared in a strict sense.

As shown in Fig. 11, two results are relatively correspondent, and small differences are due to the difference of the model scale and the propeller effects.

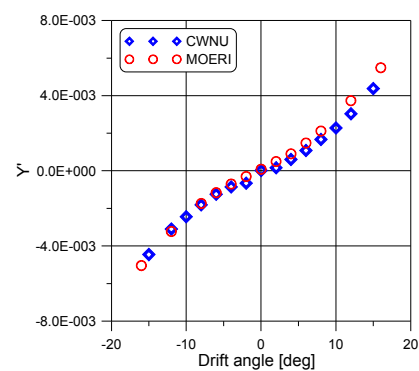

(a) Sway force

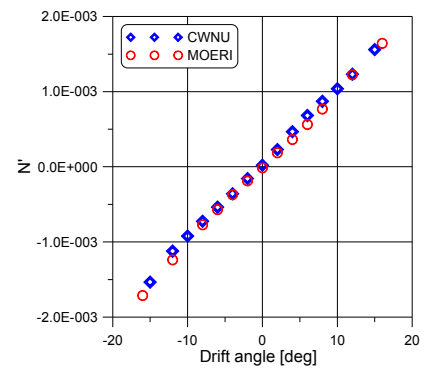

(b) Yaw moment
Fig. 11 Comparison of the drift test results from $\mathrm{CWC}$ and MOERI in case of the KCS

\subsection{Static drift test}

A static drift test was performed to obtain the hydrodynamic coefficients such as $X_{v v}{ }^{\prime}, Y_{v}{ }^{\prime}, Y_{v v v}{ }^{\prime}, N_{v}^{\prime}$ and $N_{v v v}{ }^{\prime}$. Fig. 12 shows the static drift test results of the fullloaded and the middle-loaded $\mathrm{MH}$. The draft in the full load is deeper than in the middle load. For this reason, the slopes of sway force and yaw moment in the drift test results of the full load case are steeper. 
Planar Motion Mechanism Test of the Mobile Harbor Running in Design Speed in Circulating Water Channel

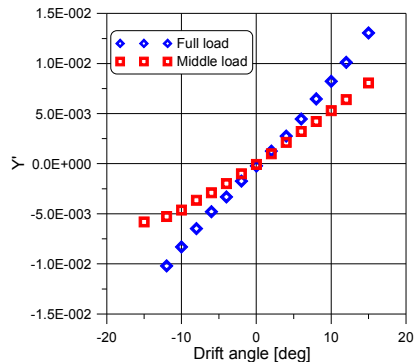

(a) Sway force

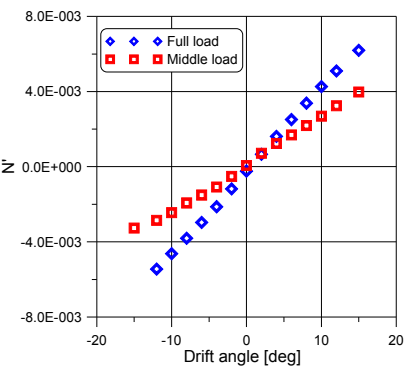

(b) Yaw moment
Fig. 12 Drift test results of the MH

\subsection{Pure sway test}

A pure sway test was performed to obtain the hydrodynamic coefficients, the so-called added mass coefficients such as $Y_{v}^{\prime}$ and $N_{v}^{\prime}$. Fig. 13 shows the in-phase hydrodynamic forces and moments acting on the full-loaded and middle-loaded $\mathrm{MH}$ when pure sway occurs. In-phase means the same phase as the sway displacement. It is general that the slope of the in-phase force and moment would be linear, while the results in Fig. 13 shows nonlinear characteristics. It is guessed because the wall effect of the CWC might occur.

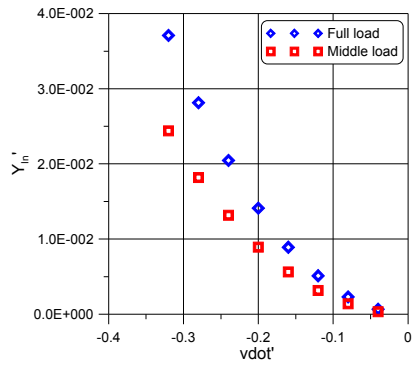

(a) Sway force

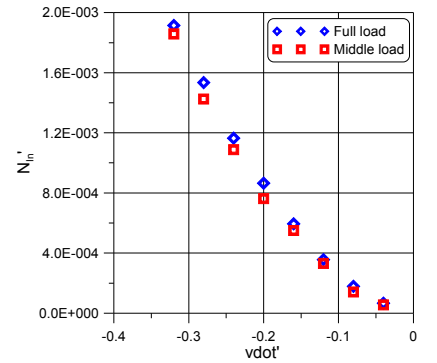

(b) Yaw moment
Fig. 13 In-phase force and moment of the pure sway test results of the $\mathrm{MH}$

\subsection{Pure yaw test}

A pure yaw test was performed to obtain the hydrodynamic coefficients such as $Y_{\dot{r}}^{\prime}, Y_{r}^{\prime}, Y_{r r r}{ }^{\prime}, N_{\dot{r}}{ }^{\prime}, N_{r}^{\prime}$, and $N_{r r r}{ }^{\prime}$. Figs. $14 \sim 15$ show the in-phase and out-of-phase hydrodynamic forces and moments acting on the full-loaded and middle-loaded $\mathrm{MH}$ when pure yaw occurs. As shown in Fig. 15(b), when $r^{\prime}$ is 0.3, a strange tendency occurred off the line even though the tests were carried out again. It must be confirmed thoroughly whether this was due to facility performance such as the narrow wall effects, or because the catamaran-type $\mathrm{MH}$ has its own characteristics.

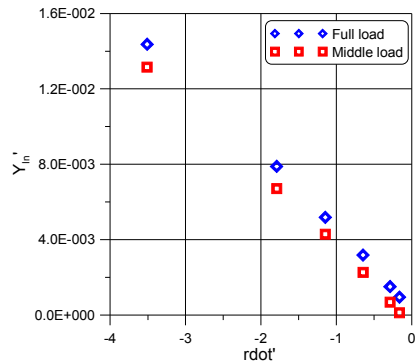

(a) Sway force

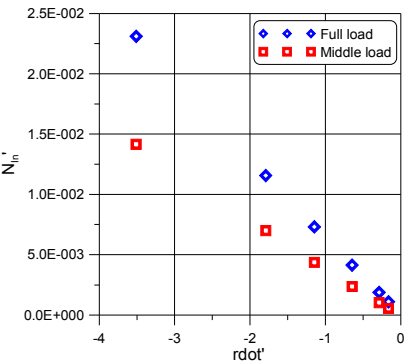

(b) Yaw moment
Fig. 14 In-phase force and moment of the pure yaw test results of the $\mathrm{MH}$

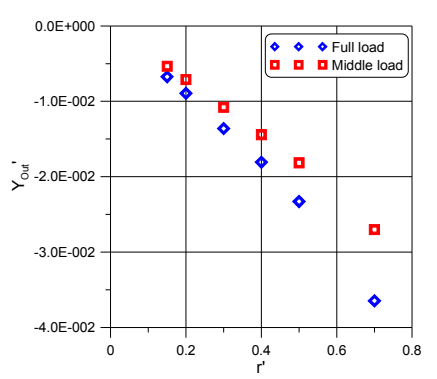

(a) Sway force

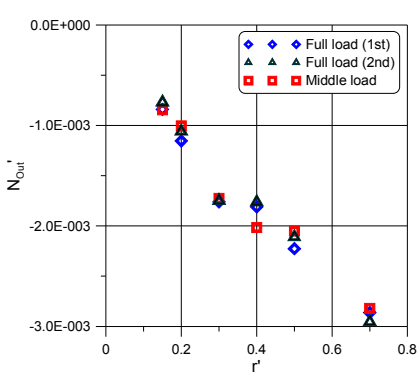

(b) Yaw moment
Fig. 15 In-phase force and moment of the pure yaw test results of the $\mathrm{MH}$

\subsection{Drift-and-yaw combined test}

A drift-and-yaw combined test was performed to obtain the coupled nonlinear hydrodynamic coefficients such as $X_{v r}{ }^{\prime}$,

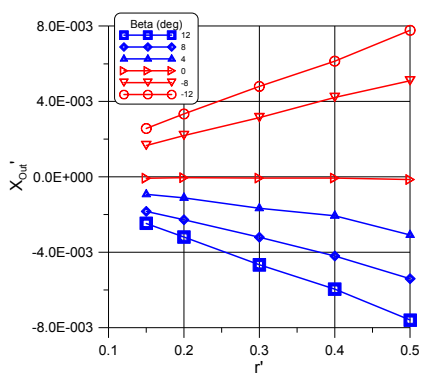

(a) Surge force

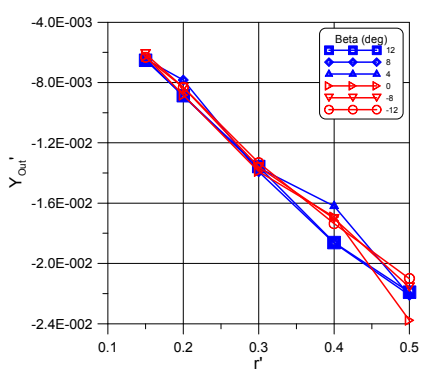

(b) Sway force
Fig. 16 Combined test results of the $\mathrm{MH}$ (Full load)

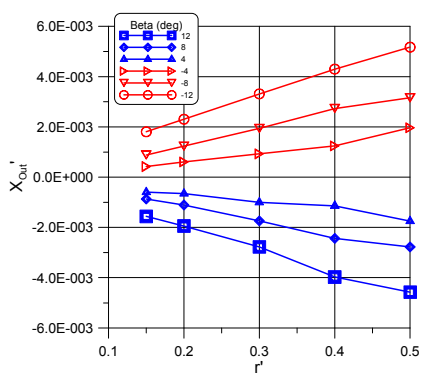

(a) Surge force

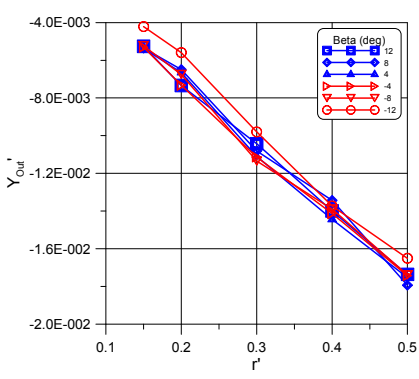

(b) Sway force
Fig. 17 Combined test results of the MH (Middle load) 
$Y_{v v r}{ }^{\prime}, Y_{v r r}{ }^{\prime}, N_{v v r}{ }^{\prime}$, and $N_{v r r}{ }^{\prime}$. Figs. 16 17 show the typical results of the hydrodynamic forces and moments acting on the full-loaded and middle-loaded $\mathrm{MH}$ when the drift-and-yaw occurs simultaneously.

\section{Test analysis}

\subsection{Hydrodynamic coefficients}

Tables $6 \sim 8$ list the estimated hydrodynamic coefficients obtained based on the PMM tests. These can be used to confirm course-keeping stability or simulate maneuvering motion if the thruster model denoted in Eq. (3) is added.

Table 6 Surge hydrodynamic coefficients

\begin{tabular}{|c|c|c|c|}
\hline \multirow{2}{*}{ Coeff. } & \multicolumn{2}{|c|}{ MH } & \multirow{2}{*}{ KCS } \\
\cline { 2 - 3 } & Full load & Middle load & \\
\hline$X_{v v}{ }^{\prime}$ & $-3.277029 \mathrm{E}-3$ & $2.357149 \mathrm{E}-2$ & $-4.142653 \mathrm{E}-3$ \\
\hline$X_{r r}{ }^{\prime}$ & $3.617010 \mathrm{E}-3$ & $2.279782 \mathrm{E}-4$ & $-4.467571 \mathrm{E}-4$ \\
\hline$X_{v r}{ }^{\prime}$ & $3.127934 \mathrm{E}-2$ & $1.682138 \mathrm{E}-2$ & - \\
\hline
\end{tabular}

Table 7 Sway hydrodynamic coefficients

\begin{tabular}{|c|c|c|c|}
\hline \multirow{2}{*}{ Coeff. } & \multicolumn{2}{|c|}{ MH } & \multirow{2}{*}{ KCS } \\
\cline { 2 - 3 } & Full load & Middle load & \\
\hline$Y_{\dot{v}}^{\prime}$ & $-4.050529 \mathrm{E}-3$ & $-6.135083 \mathrm{E}-3$ & $-2.214218 \mathrm{E}-2$ \\
\hline$Y_{\dot{r}}^{\prime}$ & $-4.183318 \mathrm{E}-3$ & $-2.814300 \mathrm{E}-3$ & $-6.764783 \mathrm{E}-4$ \\
\hline$Y_{v}^{\prime}$ & $-4.402598 \mathrm{E}-2$ & $-2.957563 \mathrm{E}-2$ & $-1.046841 \mathrm{E}-2$ \\
\hline$Y_{r}^{\prime}$ & $-2.173087 \mathrm{E}-3$ & $-5.958036 \mathrm{E}-3$ & $1.125030 \mathrm{E}-3$ \\
\hline$Y_{v v v}^{\prime}{ }^{\prime}$ & $-9.204362 \mathrm{E}-2$ & $4.044377 \mathrm{E}-2$ & $-9.909754 \mathrm{E}-2$ \\
\hline$Y_{r r r}{ }^{\prime}$ & $-2.520626 \mathrm{E}-2$ & $1.150072 \mathrm{E}-2$ & $-4.533578 \mathrm{E}-3$ \\
\hline$Y_{v v r}{ }^{\prime}$ & $7.297909 \mathrm{E}-1$ & $5.098586 \mathrm{E}-2$ & - \\
\hline$Y_{v r r}{ }^{\prime}$ & $-2.227970 \mathrm{E}-2$ & $-2.868056 \mathrm{E}-2$ & - \\
\hline
\end{tabular}

Table 8 Sway hydrodynamic coefficients

\begin{tabular}{|c|r|r|c|}
\hline \multirow{2}{*}{ Coeff. } & \multicolumn{2}{|c|}{$\mathrm{MH}$} & \multirow{2}{*}{ KCS } \\
\cline { 2 - 3 } & Full load & Middle load & \\
\hline$N_{\dot{v}}^{\prime}$ & $-2.992474 \mathrm{E}-3$ & $-2.460384 \mathrm{E}-3$ & $1.258858 \mathrm{E}-4$ \\
\hline$N_{r}^{\prime}$ & $-2.271360 \mathrm{E}-3$ & $-1.422674 \mathrm{E}-3$ & $-6.195481 \mathrm{E}-4$ \\
\hline$N_{v}^{\prime}$ & $-2.634577 \mathrm{E}-2$ & $-1.569888 \mathrm{E}-2$ & $-5.591525 \mathrm{E}-3$ \\
\hline$N_{r}^{\prime}$ & $-4.412024 \mathrm{E}-3$ & $-3.883621 \mathrm{E}-3$ & $-2.796219 \mathrm{E}-3$ \\
\hline$N_{v v v}^{\prime}$ & $2.799737 \mathrm{E}-2$ & $2.562278 \mathrm{E}-2$ & $-4.754205 \mathrm{E}-3$ \\
\hline$N_{r r r}^{\prime}$ & $-4.513715 \mathrm{E}-3$ & $-1.282502 \mathrm{E}-3$ & $4.712822 \mathrm{E}-4$ \\
\hline$N_{v v r}^{\prime}$ & $-2.576431 \mathrm{E}-2$ & $-1.402399 \mathrm{E}-2$ & - \\
\hline$N_{v r r}^{\prime}$ & $-2.853923 \mathrm{E}-3$ & $-3.503475 \mathrm{E}-3$ & - \\
\hline
\end{tabular}

\subsection{Course-keeping stability}

If it can be assumed that sway and yaw should be very small, sway and yaw coupled equations of motion can be described into the linear equations after deleting nonlinear terms in Eqs. (1) and (4) as follows:

$$
\begin{aligned}
& m\left(\dot{v}+r+x_{G} \dot{r}\right)=Y_{\dot{v}} \dot{v}+Y_{\dot{r}} \dot{r}+Y_{v} v+Y_{r} r \\
& I_{z} \dot{r}+m x_{G}(\dot{v}+r)=N_{\dot{v}} \dot{v}+N_{\dot{r}} \dot{r}+N_{v} v+N_{r} r
\end{aligned}
$$

where, the parameters in Eq. (6) are all non-dimensional values, and the primes are omitted for convenience.

In order to analyze course-keeping stability, the characteristic equation of Eq. (6) is derived as follows:

$$
A \lambda^{2}+B \lambda+C=0
$$

where, $A, B$ and $C$ are the coefficients represented by the mass, mass moment of inertia, the $x$-coordinate of the center of gravity and the hydrodynamic coefficients of the $\mathrm{MH}$. Two roots of Eq. (7) must be negative which are a necessary condition for the dynamic stability, and this can be achieved when $C$ is positive because $A$ and $B$ are always positive for conventional ships. In other words, the gain margin, which is defined as follows, should be positive.

$$
G_{h}=1-\frac{N_{v}\left(Y_{r}-m\right)}{Y_{v}\left(N_{r}-m x_{G}\right)} .
$$

Table 9 lists the results of the gain margins of the $\mathrm{MH}$ and KCS. The $G_{h}$ value for a conventional commercial ship is slightly negative as in the KCS case shown in Table 9. Since the $\mathrm{MH}$ has a small length-to-breadth ratio, this makes the maneuverability of the $\mathrm{MH}$ worse than that of the KCS.

Table 9 Gain margins

\begin{tabular}{|c|c|c|}
\hline Ship & Loading & $G_{h}$ \\
\hline \multirow{2}{*}{ MH } & Full & -4.8134 \\
\cline { 2 - 3 } & Middle & -3.1047 \\
\hline \multirow{2}{*}{ KCS } & Full & -0.4741 \\
\hline
\end{tabular}

\section{Conclusion}

In order to conduct the PMM test in CWC, test equipments such as the PMM device, a load cell, a data acquisition system, etc, were manufactured. PMM tests for the MH and the KCS were conducted, and the drift test result of KCS was compared with the one produced by MOERI. It was confirmed that static tests could be valid; however, small 
effects due to narrow wall of CWC in dynamic tests occurred, especially in the pure sway test. Using the obtained hydrodynamic coefficients, gain margins for checking the course-keeping stability were calculated. As a result, it was noted that the MH would be less course-keeping stable than the KCS.

If the CWC is bigger, the PMM test in the CWC is very convenient as well as the precision of the results are improved because there is no limit of the running range of the towing carriage in the linear towing tank. Also, it will be possible to reduce the entire test time if the test is conducted even automatically.

\section{Acknowledgements}

The work was supported by the project "Establishment of a Maneuvering Mathematical Model of Mobile Harbor's Bare Hull", which was sponsored by the Ministry of Education, Science and Technology of the Republic of Korea.

\section{References}

[1] Abkowitz M.A. (1969a), "Stability and Motion Control of Ocean Vehicles", the MIT Press, pp. 32-50, 87-95.

[2] Abkowitz M.A.(1969b), "Stability and Control of Ocean Vehicles", MIT Press, pp. I-105 I-113

[3] Fossen T.I. (1994), "Guidance and Control of Ocean Vehicles", John Wiley \& Sons, pp. 6-30.

[4] Kim S.Y. (2004), "Development of Technology on the Maneuverability and Safety for an Advanced Ship (II), The 2nd-term Report"UCN00370-2433, Korea Research Institute of Ships and Ocean Engineering, Korea Ocean Research Development Institute.

[5] Kim Y.G., Yeo D.J., Yun K.H., Oh B.I. (2009), "Prediction of Maneuverability of KCS by CPMC Captive Model Test", The Society of Naval Architects of Korea, Vol.46, No.6, pp. 553-561.

[6] Kobayashi E., Kagemoto H., Furukawa Y.(1995), "Mathematical Models of Manoeuvring Motions, Chapter 2 of Research on Ship Manoeuvrability and Its Application to Ship Design", the 12th Marine Dynamic Symposium, the Society of Naval Architects of Japan, pp. 23-90.

[7] Lewis E.V. (1989), "Principles of Naval Architecture 2nd Ed., Volume III - Motions in Waves and Controllability", The Society of Naval Architects and Marine Engineers, pp. 234-251.

[8] Sewon Engineering Co.(2009), "User's Manual for Circulating Water Channel (MODEL : HD-CWC600)".
Received 6 July 2010

Revised 25 August 2010

Accepted 6 September 2010 